Erratum: This page replaces the title page of the publication in Applied Composite Materials 11(4), 2004, 247-258.

\title{
Friction Stir Welding of Ceramic Particle Reinforced Aluminium Based Metal Matrix Composites
}

\author{
P. CAVALIERE ${ }^{1}$, E. CERRI ${ }^{1}$, P. LEO ${ }^{1}$, L. MARZOLI ${ }^{2}$ and J. DOS SANTOS ${ }^{2}$ \\ ${ }^{1}$ Department of Ingegneria dell'Innovazione, Engineering Faculty, University of Lecce, \\ Via per Arnesano I-73100,Lecce, Italy.e-mail: pasquale.cavaliere@unile.it \\ ${ }^{2}$ GKSS Forschungszentrum, Geesthacht, Germany
}

(Received 3 February 2003; accepted 2 April 2004)

Abstract. The mechanical and microstructural properties of $6061+20 \% \mathrm{Al}_{2} \mathrm{O}_{3 p}$ and $7005+10 \%$ $\mathrm{Al}_{2} \mathrm{O}_{3 \mathrm{p}}$ aluminium based metal matrix composites joined by friction stir welding were analyzed in the present study. The two materials were welded into the form of sheets of $7 \mathrm{~mm}$ thickness after T6 treatment and were tested in tension at room temperature. The microstructure of the joints was observed by optical microscopy and the fracture surfaces were analyzed by employing a scanning electron microscope equipped with field emission gun in order to study the micromechanisms involved during the deformation.

Key words: MMCs, friction stir welding, FEGSEM.

\section{Introduction}

The friction stir welding technology is going to became a very important new tool in the aircraft and automotive industry solving more of the problems related to the need of high-performance joints [1]. Such new welding technology results very useful for the joining of aluminium alloys traditionally difficult to weld (2XXX series) or materials in which the fusion techniques produce brittle dendritic structures (7XXX series) producing a strong decrease in the mechanical properties; in addition it is possible to use the FSW in the joining of dissimilar materials characterized by very different chemical compositions [2]. Many scientists demonstrated the lower distortion and presence of residual stresses in FSW joints with respect to the traditional welding techniques [3-5]. By using this technology for ceramic particle reinforced aluminium alloys this becomes a core problem due to the differences in mechanical properties of the materials.

The introduction... 